\title{
The Rotterdam AMblyopia Screening Effectiveness Study (RAMSES): compliance and predictive value in the first 2 years
}

Rikard Juttmann, on behalf of the Rotterdam Amblyopia Screening Effectiveness Study (RAMSES) steering committee*

\begin{abstract}
Background-RAMSES is a 7 year follow up study, aiming at the evaluation of the effectiveness and the efficiency of screening for amblyopia. In this first report, concerning the first 2 years of life, the compliance with the prevention programme and the positive predictive value (PPV) of the screening tests used, are presented.

Methods-All results of the standardised screening test for strabismus, applied by child healthcare physicians, within a birth cohort of 4072 Rotterdam children at the age of 9,14 , and 24 months, were registered. Children with a positive test result were referred to their general practitioner, who was asked to arrange a definitive referral to an ophthalmological centre. The results of the examinations at these centres were registered in standardised forms and served as reference for establishing the PPV.

Results-The screening was (at least one time) attended by 3958 children (97\%). 160 of these children (4\%) were referred, of whom $101(64 \%)$ visited an ophthalmological centre, so that a conclusive diagnostic evaluation was possible. For amblyopia, the predictive value of a positive test result followed by an effective referral was 0.42 .

Conclusion-Referral procedures after a positive test result in the Dutch child healthcare screening programme for amblyopia need to be improved. The Dutch screening test used to detect amblyopia exhibits a relatively favourable PPV.

(Br F Ophthalmol 2001;85:1332-1335)
\end{abstract}

Within the framework of the Dutch child healthcare system, young children are, as in many countries, periodically subjected to a routine examination of the eyes. In case of an abnormal finding, children are referred to the general practitioner and subsequently to an ophthalmological centre for further diagnostic and possibly therapeutic procedures. Whether this is an effective prevention programme for visual handicaps due to amblyopia, is not well substantiated, as Snowdon and Stewart-Brown concluded from a extended literature review. ${ }^{1}$

They also suggested that a conclusive judgment in this matter can only be reached by performing a randomised controlled screening trial (RCT). If, however, a screening programme is already performed on a large scale in a population, it is very difficult to organise an RCT for the evaluation of such a programme. Definite faith in the benefits of screening among many professionals and the public will, although based on merely circumstantial evidence, lead to strong resistance, if the screening is withheld from those who normally would have had the opportunity to participate. This was underlined by several reactions on the Snowdon and Stewart-Brown report ${ }^{2-4}$ When an RCT for assessing favourable effects of an already existing screening programme is not feasible, one has to rely on less decisive, observational studies. On this basis, the Rotterdam AMblyopia Screening Effectiveness Study (RAMSES) was started in 1996. The purpose of RAMSES is to evaluate the effectiveness and the efficiency of the amblyopia screening activities in Rotterdam child health care, as they are actually performed. The Rotterdam screening programme consists of:

- the so called VOV screening test for strabismus at the age of 9,14 , and 24 months at the child health centre (VOV is a Dutch acronym for "Vroegtijdige Onderkenning Visusstoornisen" which means "early detection of visual disorders")

- a visual acuity test, assessed by a picture chart or if feasible a Snellen chart at the age of 36 and 45 months at the child health centre

- a visual acuity test assessed by a Snellen chart at the age of 66 months at the school health centre.

All Rotterdam children, born between September 1996 and May $1997(n=4637)$ have been included in the RAMSES study and are investigated during a follow up period of 7 years. Data on the following issues are gathered:

- how many children participate in the screening

- what are the test results at the different ages

- to what extent will positive test results lead to referrals to general practitioners, ophthalmologists, and orthoptists

- which diagnostic procedures are applied

- what are the results of these procedures

- which treatment procedures will be used

- how long will treatment last

- what is the treatment compliance

- what are the results of the treatment?

Finally, at the age of 7 years the prevalence and the severity of (still existing) amblyopia in the total cohort will be evaluated by an independent orthoptist and an ophthalmologist. These results will be compared with 
Table 1 VOV ("Vroegtijdige Onderkenning Visusstoornisen” meaning "early detection of visual disorders")

\begin{tabular}{|c|c|c|c|c|c|}
\hline \multirow[b]{2}{*}{ VOV } & & \multicolumn{2}{|c|}{$\begin{array}{l}\text { First } \\
\text { examination date: }\end{array}$} & \multicolumn{2}{|c|}{$\begin{array}{l}\text { Second } \\
\text { examination date: }\end{array}$} \\
\hline & & $R$ & $L$ & $R$ & $L$ \\
\hline Corneal light reflex & symmetric: yes $(+) /$ no $(-)$ & & & & \\
\hline Cover-uncover test & $\begin{array}{l}\text { fixation movement: yes }(+) / \text { no }(-) \\
\text { recover movement: yes }(+) / \text { no }(-)\end{array}$ & & & & \\
\hline Ocular pursuit movements & $\begin{array}{l}\text { monocular: smooth }(+) \text { /not smooth }(-) \\
\text { binocular: smooth }(+) \text { /not smooth }(-)\end{array}$ & & & & \\
\hline Cornea & clear $(+) /$ not clear $(-)$ & & & & \\
\hline Pupil & $\begin{array}{l}\text { black }(+) / \text { not black }(-) \\
\text { round }(+) / \text { not round }(-)\end{array}$ & & & & \\
\hline Pupil reaction & immediate $(+) /$ not immediate $(-)$ & & & & \\
\hline
\end{tabular}

historical data on unscreened populations. Moreover, we will investigate what relations exist between differences in screening, referral, and therapy history, and the prevalence and severity of amblyopia at the age of 7 years.

In this paper the first results of this project are reported-that is, the compliance with the prevention programme and the predictive value of positive screening test results (positive predictive value (PPV)) during the first 2 years of life (so only concerning the VOV tests; at the ages of 9,14 , and 24 months).

\section{Methods}

In Rotterdam, all children are registered in the municipal register soon after birth. This information is transferred to the Rotterdam Homecare Foundation, which is organising the national child healthcare programme in this city. Subsequently all children are periodically invited to visit one of the 30 metropolitan child health centres. These visits are aimed at various screening and health education purposes and the children are examined by physicians, who completed a special training in child health surveillance. The VOV tests are incorporated in these medical examinations. For this screening the child is seated on the lap of its

Table 2 Coverage of the screening tests within the study population $(n=4072)$

\begin{tabular}{lll}
\hline Screening test & $\begin{array}{l}\text { Children } \\
\text { screened }\end{array}$ & Coverage \\
\hline At 9 month & 3619 & $89 \%$ \\
At 14 months & 3678 & $90 \%$ \\
At 24 months & 3244 & $80 \%$ \\
At least once at one of these ages & 3958 & $97 \%$ \\
\hline
\end{tabular}

Table 3 Numbers of abnormal findings

\begin{tabular}{|c|c|c|c|}
\hline Screening test & $\begin{array}{l}\text { No of children } \\
\text { screened }\end{array}$ & $\begin{array}{l}\text { Referred as result of } \\
\text { an abnormal finding } \\
\text { (for the first time) }\end{array}$ & $\%$ \\
\hline At 9 month & 3619 & 52 & 1.9 \\
\hline At 14 months & 3678 & 54 & 1.5 \\
\hline At 24 months & 3244 & 54 & 1.7 \\
\hline \multirow{2}{*}{$\begin{array}{l}\text { At least once at one } \\
\text { of these ages }\end{array}$} & & & \\
\hline & 3958 & 160 & 4.0 \\
\hline
\end{tabular}

Table 4 Proportion of referred participants that visited the ophthalmological centre

\begin{tabular}{llll}
\hline & $\begin{array}{l}\text { No of referred as } \\
\text { result of an } \\
\text { abnormal finding }\end{array}$ & $\begin{array}{l}\text { Visited the ophthalmological } \\
\text { centre; a conclusive } \\
\text { diagnosis was possible }\end{array}$ & $\%$ \\
\hline At 9 month & 52 & 41 & 79 \\
At 14 months & 54 & 36 & 67 \\
At 24 months & 54 & 24 & 43 \\
Total & 160 & 101 & 63 \\
\hline
\end{tabular}

parent, facing the investigating physician. This doctor is seated on a small chair, so that the child's eyes can be observed on an equal level. The doctor executes all the tests listed in Table 1 , by using a little fixed light. Only if the child passes all tests is the screening result considered to be negative (a normal finding). In case of a positive test (an abnormal finding) the screening is repeated within 1 month by the same doctor. All screening test results are registered in a computer file available to the RAMSES team. In case of a second positive test result the child is referred to the general practitioner, who is asked to arrange a definitive referral to one of the Rotterdam hospitals with an ophthalmological centre. In these centres conclusive diagnoses are established by an ophthalmologist on the basis of a complete ophthalmological and orthoptic examination, including if feasible a visual acuity test assessed by a picture chart or a Snellen chart and retinoscopy. These results are registered in standardised forms, which are send to the RAMSES team and serve as reference for establishing the PPV.

\section{Results}

Of the 4637 Rotterdam children, born between September 1996 and May 1997, 565 moved from the city within $2 \frac{1}{2}$ years. This report deals with the 4072 remaining children.

The coverage of the screening tests during the first 2 years of life is summarised in Table 2. The attendance at the regular visits to the child health centre, during which the VOV screening is performed, turns out to be high. Ninety seven per cent of all children visited the centre at least once at the age of 9,12 , or 24 months. One hundred and sixty children exposed to screening $(4.0 \%)$ were referred as a result of an abnormal finding (Table 3). As presented in Table 4, 101 of these children $(63 \%)$ visited an ophthalmological centre, so that a conclusive diagnostic evaluation was possible. Fifty three did not visit the ophthalmologist at all; six failed control visits, so that a conclusive diagnostic evaluation was not possible. The results of the diagnostic evaluation at the ophthalmological centre and the entailing predictive values of a positive screening test followed by an effective referral are presented in Table 5. Sixty four out of the 101 children with a positive screening test followed by an effective referral did have some kind of ophthalmological disorder. Of these children, however, 22 did not have any symptoms of 
Table 5 Results of the evaluation at the ophthalmological centre predictive value of a positive screening test followed by an effective referral (PPV)

\begin{tabular}{llllll}
\hline Screening test & $\begin{array}{l}\text { No evaluated by } \\
\text { ophthalmologist }\end{array}$ & $\begin{array}{l}\text { Visual disorder } \\
\text { not amblyopia }\end{array}$ & $\begin{array}{l}\text { (Probably) } \\
\text { amblyopia }\end{array}$ & $\begin{array}{l}\text { PPV all visual } \\
\text { disorders }\end{array}$ & $\begin{array}{l}\text { PPV } \\
\text { amblyopia }\end{array}$ \\
\hline At 9 months & 41 & 7 & 15 & 0.54 & 0.37 \\
At 14 months & 36 & 9 & 12 & 0.58 & 0.34 \\
At 24 months & 24 & 6 & 15 & 0.88 & 0.62 \\
Total & 101 & 22 & 42 & 0.63 & 0.42 \\
\hline
\end{tabular}

amblyopia, but of other disorders such as mild forms of ptosis, haemangioma, and ocular infections. The other 42 children did have clear indications for amblyopia, such as strabismus in 33 cases and refraction disorders in 20 cases. So the predictive value of a positive screening test (PPV), followed by a effective referral for any ophthalmological disorder is 0.63 and for amblyopia 0.42 .

\section{Discussion}

COMPLIANCE WITH PREVENTION ACTIVITIES

The numbers of the target population reached by the various activities of a prevention programme is indicative of the possible effectiveness of such a programme. Although the coverage of the screening examination itself is relatively high, the following referral procedure appears to be less good. One third of all children with a positive screening test result are not conclusively evaluated at an ophthalmological centre and may fail to profit from early treatment for amblyopia. Whether this is attributable to parents failing to visit the general practitioner and the ophthalmological centre or to an unnecessary expectant attitude of general practitioners themselves is not clear. Since it was our aim to evaluate the amblyopia prevention programme, as it is actually performed, the RAMSES team did not investigate the referral procedures, so as to avoid observation bias.

Considering the extent of non-compliance with the referral procedures and its possible impact on the effectiveness of the programme as a whole, improvement of this part of the prevention programme appears to be recommendable. Probably, screening for amblyopia in the Netherlands suffers from too many intermediate steps between referral and application of the gold standard, which, of course, is a frequent problem with screening in general.

PREDICTIVE VALUE OF A POSITIVE SCREENING TEST (POSITIVE PREDICTIVE VALUE: PPV)

The PPV provides an indication for a specific efficiency aspect of the screening programme rather than for its effectiveness: This test property (or rather the difference between the PPV and 1) is determined for the number of screening participants for whom the screening is not profitable but merely inconvenient and unnecessarily alarming - the participants with false positive test results (false positives).

To appreciate the PPV established in this study a comparison with similar data from studies on other child healthcare screening programmes is helpful. In Table 6 the results of our study are compared with data on PPV and false positives published in studies on the following screening programmes: screening for phenylketonuria (PKU) and congenital hypothyroidism (CHT) by neonatal blood examination, ${ }^{56}$ screening for perceptive hearing impairments with the Ewing distraction test, ${ }^{7}$ screening for congenital heart malformations by physical examination, ${ }^{8}$ screening for idiopathic adolescent scoliosis by the standard forward bending test, ${ }^{9}$ and screening for developmental dysplasia of the hip by detection of limitations of hip abduction and differences in the length of the legs. ${ }^{10}$ The data are presented in order of increasing incidence of the relevant disorder. If test properties, especially the PPV, were fixed, the number of false positives would increase according to rise in incidence. However, the VOV screening test exhibits a quite favourable PPV, compared with most other child healthcare screening tests, resulting, in spite of a relatively high incidence, in a relatively limited number of false positives. Of course, screening for very rare disorders, such as PKU and CHT, causes very few false positives, even if the PPV is relatively low, as is the case in CHT screening. Also screening for congenital heart malformations causes, in spite of a low PPV, fewer false positives than screening for amblyopia, because of a relatively low incidence. Screening for other infrequent disorders, such as perceptive hearing impairments and idiopathic adolescent scoliosis, however, causes substantially more false positives than the VOV test, because of very poor PPVs. Screening for developmental dysplasia of the hip, which has a incidence similar to amblyopia, causes an eightfold increase in false positives compared with the VOV test, because of a less favourable PPV.

\section{Conclusion}

The referral procedures after a positive test result in Dutch child healthcare screening for amblyopia must be improved. The VOV screening test for amblyopia exhibits a more favourable PPV than several other child healthcare screening tests. To establish further

Table 6 Literature data on positive cumulative incidence, number of false positive test results, predictive value (PPV) and test sensitivity in child healthcare screening programmes for several disorders, per 1000 children

\begin{tabular}{llllll}
\hline & & Incidence 0/00 & False positives & PPV & Sensitivity \\
\hline Phenylketonuria & Verkerk $1995^{5}$ & 0.06 & 0.12 & 0.50 & 0.99 \\
Congenital hypothyreodia & Verkerk $1996^{6}$ & 0.29 & 1.7 & 0.17 & 0.98 \\
Perceptive hearing impairments & van Leerdam $1998^{7}$ & 2 & 70 & 0.024 & 0.86 \\
Congenital heart malformations & Juttmann $1998^{8}$ & 4 & 15 & 0.13 & 0.57 \\
Idiopathic adolescent scoliosis & Yawn $1999^{9}$ & 4 & 42 & 0.05 & 0.54 \\
Developmental dysplasia of the hip & Boere-Boenekamp 1998 & 37 & 173 & 0.15 & 0.83 \\
Amblyopia & present paper & $20-40^{\star}$ & 23 & $0.42 \dagger$ & not yet known \\
\hline
\end{tabular}

*Based on incidence estimations from the international literature.

†PPV calculated only for amblyopia and not for other ophthalmic disorders. 
insight in the effectiveness and efficiency of the Dutch child healthcare screening programme for amblyopia, subsequent results of the RAMSES study are awaited.

\section{Rotterdam Amblyopia Screening Effectiveness Study (RAMSES) steering committee}

$\mathrm{P} J$ van der Maas, $\mathrm{MD}, \mathrm{PhD}$, and $\mathrm{R} \mathrm{E}$ Juttmann, $\mathrm{MD}$, $\mathrm{PhD}$, Department of Public Health Erasmus University Rotterdam; VK Lantau, CO, Foundation Early Detection of Visual Disorders, Amsterdam; HJ Simonsz, MD, $\mathrm{PhD}$, University Hospital Rotterdam; JTN de Faber MD, Rotterdam Eye Hospital; CM van der Werf-de Koning, $\mathrm{MD}$, Rotterdam Homecare Foundation; WC Hoogeveen MD, Rotterdam Municipal Health Department.

The efforts of all Rotterdam child healthcare physicians, orthoptists, and ophthalmologists are gratefully acknowledged.

1 Snowdon SK, Stewart-Brown SL. Preschool vision screening. Health Technol Assess 1997;1:1-83.
2 Rahi JS, Dezateux C. The future of preschool vision screening services in Britain. BMF 1997;315:1247-8.

3 Lee J, Adams G, Sloper J, et al. Cost effectiveness of screening for amblyopia ia a public health issue. BMF 1998;316: 937.

4 Fielder AR. Review article did not separate review and implementation processes. BMF 1998;316:937.

5 Verkerk PH. 20-year national screening for phenylketonuria in the Netherlands. National Guidance Commission PKU. Ned Tijdschr Geneeskd 1995;139:2302-5.

6 Verkerk PH, Zaal MAE van. Report on screening for congenital hypothyroidia on children born in 1995 and third measurement 1990 (Rapportage van de screening op congenitale hypothyreoidie bij kinderen geboren In 1995 en 3e meetpunt 1990). Leiden: TNO-PG, 1996

7 Leerdam FJM van. Standard guidelines for early detection of hearing impairments in child health care 0-19 years. (JGZ-standaard vroegtijdige opsporing gehoorstoornissen 0-19 jaar) Bohn Stafleu Van Loghum Houten/Diegem, Netherlands, 1998.

8 Juttmann RE, Hess J, Looman CW, et al. Screening for congenital heart malformation in child health centres. Int $\mathcal{F}$ Epidemiol 1998;27:989-94

9 Yawn BP, Yawn RA, Hodge D, et al. A population-based study of school scoliosis screening. FAMA 1999;282:1427-32.

10 Boere-Boonekamp MM, Kerkhoff TH, Schuil PB, et al. Early detection of developmental dysplasia of the hip in the Netherlands: the validity of a standardized assessment protocol in infants. Am F Public Health 1998;88:285-8. 